\title{
A BAIXA INCIDÊNCIA DE PESQUISA EMPÍRICA E A CULTURA MANUALESCA COMO OBSTÁCULOS PARA O DESENVOLVIMENTO DO DIREITO
}

\section{THE LOW INCIDENCE OF EMPIRICAL RESEARCH AND THE TEXTBOOK CULTURE AS A HINDRANCE TO THE DEVELOPMENT OF LAW}

Recebido: 06.10.2017

Aprovado: 04.12.2017

José Maria de Morais Borges Neto* José Eduardo Barroso Colácio** Fayga Silveira Bedê $\hat{e}^{* * *}$

RESUMO: O presente estudo busca compreender as razões pelas quais a pesquisa jurídica no Brasil permanece relativamente infensa à pesquisa empírica. Percebe-se que, em outras matrizes jurídicas, como é o caso dos Estados Unidos, a adoção dos estudos de campo já se encontra muito mais incorporada em seu repertório, tendo em vista o papel central da jurisprudência e o modo como ela reverbera na Academia, em termos de análise do discurso produzido pelas suas cortes. No caso do Brasil, muito embora se reconheça uma série de iniciativas relevantes no sentido de promover a adoção da pesquisa empírica no Direito, de modo geral, ainda se tratam de práticas isoladas, fruto dos esforços envidados por grupos de excelência. Compreende-se que a dificuldade de se imiscuir novas práticas de pesquisa de campo no bojo da pesquisa jurídica brasileira tem causas multifatoriais. Para os limites do presente estudo, reflete-se sobre a hipótese de a cultura manualesca - cujo maior esteio reside em meros argumentos de autoridade - constituir um dos principais fatores de inibição à pesquisa empírica. De acordo com essa hipótese, a ser testada em trabalhos posteriores, a tendência dogmatizante dos manuais tornaria a pesquisa jurídica mais autorreferente e menos permeável aos estudos de campo.

Palavras-chave: Pesquisa empírica. Desenvolvimento do Direito. Cultura de Manual.

ABSTRACT: The present study seeks to understand the reasons why legal research in Brazil remains relatively unfriendly toward empirical research. In other legal domains, such as the case in the United States, the resource of field studies is already much more incorporated into its repertoire, given the central role of jurisprudence and the way it reverberates in the Academy, in terms of analysis of the discourse produced by their courts. In the case of

\footnotetext{
* Mestrando em Direito pela UNICHRISTUS. Advogado militante. Email: jose@borgesneto.com.br

${ }^{* *}$ Mestrando em Direito Processual e Desenvolvimento (Unichristus).Pós-graduado lato sensu em Direito Processual Civil e em Direito Administrativo e Processo Administrativo (UNIFOR). Advogado em Fortaleza-CE. E-mail: <eduardocolácio@yahoo.com.br.

*** Professora do Mestrado em Direito da Unichristus. Doutora em Sociologia pela UFC. Mestre em Direito pela UFPR. Editora-chefe da Revista Opinião Jurídica. Email: faygabede@hotmail.com.
} 
Brazil, although a series of relevant initiatives are recognized to promote the adoption of empirical research in the Law, in general, they are still isolated practices, the result of the efforts made by groups of excellence. It is understood that the difficulty to introduce new field research practices within the scope of Brazilian legal research has many causes. For the limits of the present study, it is reflected on the hypothesis that the textbook culture, whose main foundation are mere arguments of authority, constitutes one of the main factors of inhibition to the empirical research. According to this hypothesis, to be tested in later works, the dogmatic tendency of textbooks would make legal research more self-referential and less permeable to field studies.

Keywords: Empirical research. Development of Law. Textbook Culture.

\section{INTRODUÇÃO}

Em evidente contraste com outras áreas do conhecimento científico, o direito, especialmente no Brasil, realiza escassa e insatisfatória produção quando o tema é pesquisa de campo. Mesmo considerando universos científicos afins, como os da área de humanas, fica evidente a enorme diferença produtiva. A pesquisa empírica na área jurídica, ou a falta dela, é um problema que os pesquisadores e operadores do direito têm de enfrentar, sobretudo pela fragilidade que tal postura enseja à ciência do direito, quando comparado com outras áreas do conhecimento.

As faculdades de direito, mesmo as consideradas "de ponta", preparam seus corpos discentes a atuar como operadores jurídicos, para que entendam como funciona o sistema normativo e possam utilizá-lo na sua prática, com a finalidade de solucionar os problemas concretos que lhes serão postos. O conteúdo do ensino jurídico, desta forma, se coloca como quase que meramente dogmático, havendo escasso estímulo à pesquisa de campo, que vise a compreender como o direito se manifesta na realidade ou, melhor, como as manifestações empíricas podem contribuir para a dogmática.

Não se pode ignorar, entretanto, os consistentes avanços na pesquisa empírica em direito nas últimas duas décadas. Isso pode ser notado com o lançamento de periódicos especializados sobre a temática, a criação de comunidades científicas organizadas que promovem encontros periódicos e o aparecimento de uma disponibilidade de recursos financeiros para subsidiar Pesquisas Empíricas em Direito - doravante denominadas de PED.

Entretanto, claramente constatam-se uma série de barreiras que engessam as pesquisas jurídicas e redundam nessa preocupante realidade de isolamento científico. Este trabalho busca analisar a hipótese da cultura de manual presente no ensino jurídico tradicional como um possível fator inibidor da realização de PED. Essa dificuldade acaba por dragar a ciência do direito em um ciclo vicioso muito prejudicial ao seu desenvolvimento, no qual se verifica um verdadeiro desestímulo técnico, financeiro e cultural à pesquisa de campo.

Para as finalidades deste estudo, analisar-se-á, inicialmente, a pesquisa jurídica nos Estados Unidos, que já há mais de um século realiza pesquisas de campo, e que 
tem consistente produção neste sentido, buscando aferir quais os fatores que podem fomentar essa realidade, e especificamente perquirindo se a tradição jurídica inglesa, do direito consuetudinário, enseja ambiente propício para a PED.

Após, abordar-se-á analiticamente o desenvolvimento da PED no Brasil, buscando referenciais históricos e culturais que tenham contribuído para o sufocamento da pesquisa de campo em direito.

Por fim, será levantada a hipótese para o problema de partida proposto (por que no Brasil se realiza tão pouca pesquisa de campo em direito?), qual seja, a arraigada cultura de manual presente no trato e ensino da ciência jurídica, como um elemento que finda por afastar o pesquisador dos problemas da realidade, obliterando a acepção de problemas práticos como problemas jurídicos.

Para ilustrar o enclausuramento da ciência jurídica no Brasil, e, por que não dizer, a empáfia de boa parte dos seus operadores, é caricato o caso citado por Veronese, ocorrido na Faculdade de Direito do Recife:

Isso é compreensível pela história descrita por Joaquim Falcão sobre uma palestra de Gilberto Freire na Faculdade de Direito do Recife, atualmente parte da Universidade Federal de Pernambuco. Quando do ocorrido, Gilberto Freire já era um reconhecido cientista social. Ele havia sido convidado para dar uma conferência no Salão Nobre daquela Faculdade. Quando o cientista social se precipitou para adentrar o Salão, pôde contemplar uma faixa estendida na grande mesa. Dizia a faixa: “fora meteco!". Meteco, em grego, significa estrangeiro. Desse modo, os alunos da Faculdade de Direito do Recife diziam para Gilberto Freire que, naquela mesa, somente juristas podiam ter a palavra. Mais, diziam que a "ciência"do direito não precisava de conselhos da Antropologia ou da Sociologia. Vivia bem... Isoladamente! (VERONESE, 2011, p. 182).

\section{A PESQUISA JURÍDICA NO CONTEXTO NORTE-AMERICANO}

A difícil relação entre as instituições de ensino jurídico e a pesquisa de campo não é uma exclusividade brasileira. Historicamente, no mundo inteiro, independente da matriz da cultura jurídica dominante, há uma tendência geral de enclausuramento no trato acadêmico da ciência do direito, de forma a insulá-la do ambiente social, da realidade, o que representa uma vistosa contradição, na medida em que se trata de um ramo das ciências humanas.

De fato, a forte tradição positivista reinante no último século parece ter esvaziado qualquer ímpeto de sair do claustro. Ao limitar o âmbito do direito ao ordenamento jurídico, e ao classificá-lo exatamente como o conjunto de normas postas que regulam a conduta humana (KELSEN, 2009), o positivismo jurídico minimiza o objeto de estudo do direito. ${ }^{1}$ É como se o ordenamento jurídico contivesse, em si, as verdades a serem

1 Ainda sobre a limitação que o positivismo jurídico encerra à pesquisa empírica na área do direito, pertinente a observação de Silva (2016, p. 27): "Na medida em que assim estabelece e caracteriza as normas e o ordenamento como objetos do conheci- mento jurídico, o positivismo também delimita os termos (métodos) pelos quais o sujeito deve com eles se relacionar. Ao fazê-lo, o positivismo impõe duas exigências epistemológicas ao jurista. Por um lado, este deve cingir-se ao exame da ordem normativa emanada a partir do Estado - a forma pela qual o poder político passou a ser exercido na modernidade, em contraste com formas mais tradicionais ou místicas, típicas de sociedades prémodernas. O direito, em suma, só pode ser encontrado em leis, decretos, portarias, sentenças, acórdãos, etc. Por outro 
buscadas pelo cientista ou aplicador do direito, de forma que não haveria sequer a necessidade de pesquisa da realidade. Em verdade, a pesquisa que extrapolasse o âmbito normativo era até desaconselhada ao jurista (SILVA, 2016).

Há, entretanto, um destaque a ser feito quando o assunto é PED: os países de tradição jurídica anglo-saxônica apresentam uma tendência à realização, em maior escala, de pesquisas empíricas, o que pode ser explicado pela necessidade de acesso, pelo operador do direito, a toda uma realidade construída a partir de casos anteriormente apreciados, o que enceta, sem dúvida, um viés prático ao estudo jurídico.

Por ser o exemplo mais representativo da realização de PED, será analisado o caso dos Estados Unidos, que, em termos comparativos, já têm uma produção acadêmica de caráter empírico mais sistemática que a nossa. ${ }^{2}$

Já nos anos 20 do século passado, a comunidade jurídica norte americana iniciou um movimento denominado realismo jurídico, corrente de pensamento que se contrapunha ao excessivo formalismo jurídico, buscando estudar, portanto, os fatos empíricos e realidades práticas que moviam o direito, focando as suas análises não no que a dogmática tradicional orientava, mas no que de fato era vivido e experimentado no diaa-dia. ${ }^{3}$ Para os realistas "Legal rules and reasons figure simply as post-hoc rationalizations for decisions reached on the basis of non-legal considerations.” (LEITER, 2004, p. 51).

Embora o realismo jurídico não tenha, como consentem os estudiosos, cumprido a sua promessa e produzido considerável pesquisa empírica de expressividade, (SCHLEGEL, 1995; LEEUW, 2015) certamente arou terreno para os próximos movimentos acadêmicos de aproximação da ciência jurídica com a pesquisa de campo. De fato, nos anos 6o surgiu a Law and Society Association, e nos anos 90 o Law and Economics, o New Legal Realism e o Empirical Legal Studies, todos movimentos científicos que, em comum, propagam a realização sistêmica de pesquisa de campo qualificada no âmbito do direito e a aproximação do direito com as ciências sociais e políticas, a economia e a psicologia. (MILES; SUSTEIN, 2008).

Deve-se registrar, ainda, que essas correntes, sobretudo a partir dos anos 90, trouxeram inovações sobretudo na qualidade e métodos utilizados para a realização das pesquisas, constatando-se também uma mudança vetorial a partir do crescente interesse das faculdades de direito pela pesquisa empírica. Essa constatação é feita pelos professores

lado, o conhecimento da ordem normativa assim delimitada deve ter por finalidade última e exclusiva a identificação dos deveres que ela objetivamente estatui."

$2 \mathrm{O}$ estímulo à pesquisa empírica em direito nos Estados Unidos pode ser percebido pelo ranking das faculdades de Direito baseado no chamado ELS (Empirical legal scolarship), que é a pesquisa de campo jurídica (GEORGE, 2005).

$3 \mathrm{O}$ professor de filosofia do direito e fundador do movimento Law and Philosophy Brian Leiter, bem analisa o realismo jurídico Americano: "American Legal Realism was the most important indigenous jurisprudential movement in the United States during the zoth century, having a profound impact not only on American legal education and scholarship, but also on law reform and lawyering. Unlike its Scandinavian cousin, American Legal Realism was not primarily an extension to law of substantive philosophical doctrines from semantics and epistemology. The Realists were lawyers (plus a few social scientists), not philosophers, and their motivations were, accordingly, different. As lawyers, they were reacting against the dominant 'mechanical jurisprudence' or 'formalism' of their day. 'Formalism', in the sense pertinent here, held that judges decide cases on the basis of distinctively legal rules and reasons, which justify a unique result in most cases (perhaps every case). The Realists argued, instead, that careful empirical consideration of how courts really decide cases reveals that they decide not primarily because of law, but based (roughly speaking) on their sense of what would be 'fair' on the facts of the case."(LEITER, 2004, p. 50). 
Mark Suchman (Brown University) e Elisabeth Mertz (Wisconsin Law School):

Thus, the new legal empiricism's novelty lies less in its method and subject matter than in its institutional locus and intellectual agenda: ELS and NLR, we argue, are best understood as efforts to legitimate empirical research within the legal academy itself. This new context demands new tactics and new framings, even for investigations that are methodologically and conceptually continuous with what has gone before (SUCHMAN; MERTZ, 2010, p. 556).

Postas essas premissas, nos limites estritos dos objetivos deste estudo, importa verificar como a PED vem sendo desenvolvida no ambiente jurídico brasileiro.

\section{PESQUISA EMPÍRICA NO BRASIL}

\subsection{UM BREVE REFERENCIAL TEÓRICO}

Antes de mais nada, é necessário esclarecer o referencial teórico usado, daqui para frente, quando se tratar de pesquisa jurídica empírica. É que existe uma discussão acerca da diferenciação entre pesquisa empírica em direito e pesquisa empírica com o direito, sendo a primeira aquela que tenha como resultado a produção de um conhecimento propriamente jurídico e a segunda aquela pesquisa que, embora relevante para a ciência do direito, produz conhecimento externo, que pertence a outras áreas do conhecimento.

Tudo depende de como é concebido o direito. Se ele é compreendido na ótica Kelseniana (KELSEN, 2009), certamente a pesquisa empírica é irrelevante ao mundo do direito, e portanto poderia ser realizada utilizando-se do direito, com o direito, não tendo o seu resultado relevância jurídica. Se, por outro lado, o direito é concebido como um fenômeno social, empírico e não puramente descritivo, o valor da pesquisa de campo é fundamental, e aí sim se pode falar em pesquisa em direito.

O presente estudo se filia a esta segunda linha epistemológica, considerando mais a empiria como um elemento central do direito, utilizando-se para tanto da perspectiva de Ross (1959), para quem a própria validade do direito é condicionada à realidade, de forma que a ciência jurídica somente pode ser compreendida a partir de sua aplicação. ${ }^{4}$

Para que fique clara a posição assumida, fundamental a crítica do Professor Marcos Severino Nobre:

A dogmática é o núcleo da investigação científica no âmbito do direito. Embora a afirmação não seja pacífica nem consensual, tampouco tem pretensão de originalidade. $\mathrm{E}$ as divergências e diferenças se põem quando se trata de explicitar qual é a natureza da investigação dogmática. De saída, a fim de evitar

\footnotetext{
4 "The leading idea of this work is to carry, in the field of law, the empirical principles to their ultimate conclusions. From this idea springs the methodological demand that the study of law must follow the traditional patterns of observation and verification which animate all modern empirical science; and the analytical demand that the fundamental legal notions must be interpreted as conceptions of social reality, the behaviour of man in society, and as nothing else."(ROSS, 1959. p. 9).
} 
mal-entendidos, gostaria de esclarecer que não proponho um entendimento científico do direito a partir de perspectivas como a da sociologia, da história ou mesmo da filosofia. Não se trata de submeter o direito a nenhuma dessas perspectivas disciplinares em particular, o que lhe destruiria a especificidade. Trata-se antes de ampliar o conceito de dogmática e, portanto, seu campo de aplicação, de modo que os pontos de vista da sociologia, da história, da antropologia, da filosofia ou da ciência política não sejam exteriores, tampouco "auxiliares", mas se incorporem à investigação dogmática como momentos constitutivos (NOBRE, 2004, p. 12).

\subsection{ONDE ESTAMOS?}

A produção científica na área jurídica, e aqui não se está a referir, ainda, exclusivamente acerca da pesquisa de campo, é vista com certa desconfiança por outras áreas do conhecimento. Em relatório produzido pelo Conselho Nacional de Desenvolvimento Científico e Tecnológico (CNPq), nos idos de 1984, constatou-se o seguinte: "Numa sociedade em que as faculdades de direito não produzem aquilo que transmitem, e o que se transmite não reflete o conhecimento produzido, sistematizado ou empiricamente identificado, a pesquisa jurídica científica, se não está inviabilizada, está comprometida." (BASTOS, 1991 apud NOBRE, 2004, p. 7).

Ainda sobre esse olhar vacilante sobre o que é produzido pela academia jurídica, Marcos Nobre bem assinala, também, uma falta de metodologia científica na produção teórico-jurídica, constatando que "os cientistas sociais costumam olhar com desconfiança a produção teórica em direito, já queaí não se encontram os padrões científicos requeridos [...]." (NOBRE, 2004, p. 6).

No próximo tópico, será abordada uma hipótese para a ocorrência desse fenômeno na ciência jurídica brasileira. Por ora, é preciso fazer alguns registros históricos da pesquisa empírica em direito no país. Na década de 1970, destaca-se uma corrente de trabalhos empíricos desenvolvidos sobretudo na área da sociologia jurídica. ${ }^{5}$

Somente com a promulgação da Carta Magna de 1988, que positivou uma plêiade de direitos e garantias fundamentais, é que se verificou um crescente interesse da comunidade jurídica em verificar, na prática, a efetivação dos mesmos, momento no qual, parte da academia, superando resistências, voltou-se à pesquisa de campo, surgindo também, neste momento, possibilidade de financiamento das pesquisas, via CNPq, conforme bem destaca Faria e Campilongo (1991 apud HORTA; ALMEIDA; CHILVAQUER, 2014, p. 165):

[...] as grandes transformações que atingiram o Brasil nos idos de 1980 e 1990 fizeram com que muitos juristas - pondo em questão as fronteiras tradicionais do Direito com as Ciências Sociais - substituíssem as abordagens lógicoformais por outras mais críticas e problematizantes.

5 Em artigo publicado na Revista de Estudos Empíricos em Direito, Ricardo Lins e Horte, Vera Ribeiro de Almeida e Marcelo Chilvarquer nomeiam alguns expoentes setentistas da pesquisa jurídica empírica: "[...] Lima Arruda Jr., Luís Warat, José Eduardo Faria, Celso Campilongo, José Geraldo de Sousa Jr., Luciano.”(HORTA; ALMEIDA; CHILVARQUER, 2014, p. 165). 
E prossegue:

A consolidação do financiamento da pesquisa jurídica via Conselho Nacional de Desenvolvimento Científico e Tecnológico (CNPq) contribuiu para o surgimento de uma embrionária institucionalização da pesquisa jurídica apoiada nas ciências sociais. Por sua vez, a criação do Conselho Nacional de Pesquisa e Pós-Graduação em Direito (CONPEDI), em 1992, e a realização, desde então, de um Congresso Nacional anual contribuíram para a socialização de pesquisas na pós-graduação em Direito e a construção de arranjos institucionais - embora em seus primeiros anos a defesa da especificidade da pesquisa jurídica tenha refutado a aproximação com outros saberes (HORTA; ALMEIDA; CHILVAQUER, 2014, p. 165).

Esse ambiente também proporcionou o início da realização de PED no Brasil, ainda na década de 1990, por universidades como a Federal Fluminense e o Instituto Universitário de Pesquisa do Rio de Janeiro (IUPERJ), através de seu Centro de Estudos em Direito e Sociedade (CEDES). (HORTA; ALMEIDA; CHILVAQUER, 2014). A PED vivenciou, a partir daí, um notável avanço, com a criação de revistas científicas especializadas na temática, um razoável incentivo acadêmico para tanto e a formação de células de pesquisas que promovem encontros regulares, cada vez mais acolhidos por profissionais que lidam com o Direito.

De fato, nas duas últimas décadas, verifica-se um crescente aumento nas pesquisas de campo na área jurídica. Isto pode ser constatado pelo estudo apresentado por Guilherme Duarte Jardim, no IV Encontro de Pesquisa Empírica em Direito, em 2014, respondendo a uma chamada pública da Rede de Pesquisa Empírica em Direito (REED) e do Instituto de Pesquisa Econômica Aplicada (IPEA) para que professores e profissionais do direito realizassem um mapeamento das PEDs no Brasil, tendo chegado à seguinte constatação:

A pesquisa, parcialmente realizada, levantou o quanto se produziu de pesquisa empírica em Direito no Brasil. Com o uso de um crawler (software) para automação de coleta e com o uso de palavras-chave como "pesquisa empírica", "enfoque empírico", "direito", descobriu-se que houve um crescimento quase exponencial do que foi produzido em revistas nacionais, a partir de 2003. Mais, realizando um levantamento por área, também se identificou o mesmo crescimento na série temporal (JARDIM, 2014, p. 176)

O estudo apresentado, bem mais complexo do que o breve panorama que ora se recorta, ${ }^{6}$ compilou os dados dos mais diversos ramos do direito e chegou ao seguinte gráfico:

6 Conforme bem pondera o autor da pesquisa, o só fato de um estudo conter, em seu título ou corpo do texto, uma ou algumas das expressões relacionadas ao empirismo, não permite automaticamente deduzir se tratar de uma pesquisa de campo. Em verdade, os números são devem ser analisados como uma tendência de crescimento, com sujeição à alargada margem de erro. 


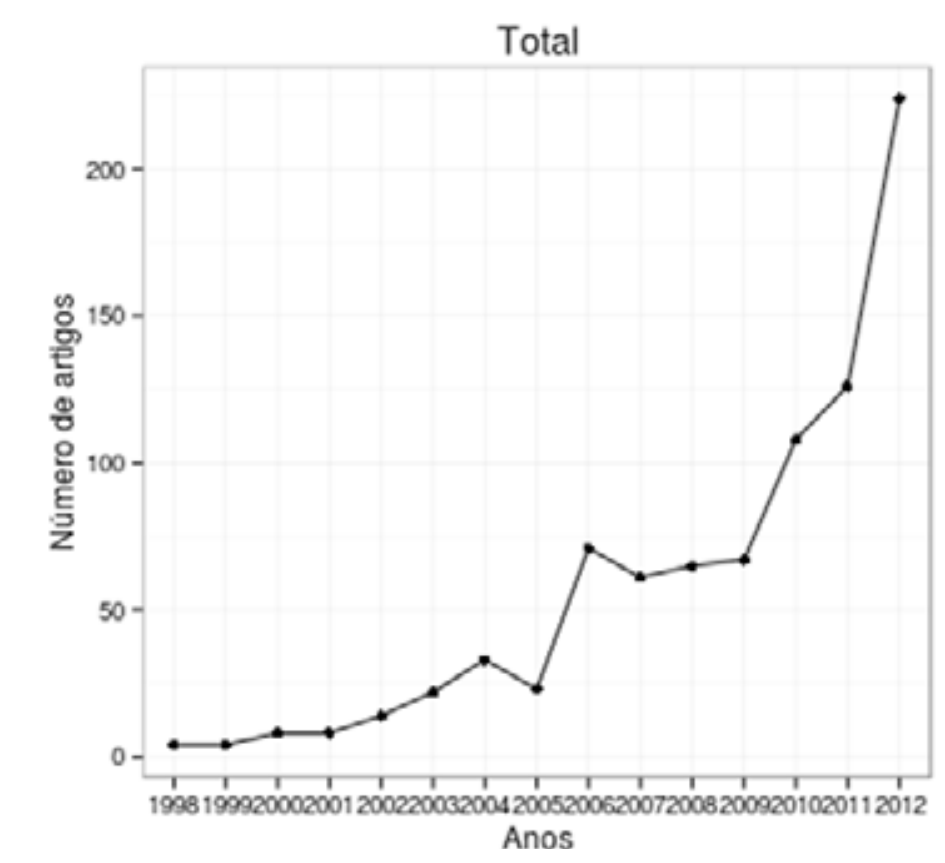

Gráfico 1 - Análise de publicações de PED no Brasil de 1998 a 2012. Fonte: (JARDIM, 2014. p. 173-192).

Esses números crescentes de PEDs no Brasil podem ser atribuídos, dentre outros fatores já assinalados, à superação de algumas dificuldades históricas do meio acadêmico jurídico, como o isolamento do direito em relação a outras áreas do conhecimento, o que aos poucos - por uma necessidade mais do direito, do que das outras ciências, diga-se de passagem - vem diminuindo.

Esse aumento, embora expressivo, ainda não eleva a ciência do direito, em sua produção científica empírica, ao patamar de outras áreas das ciências, sobretudo as humanas e sociais, para nem mencionar o caso das ciências da saúde. Ou seja, embora haja consenso acerca do vertiginoso aumento, nas últimas décadas, da PED, que caminha na superação de muitos dos entraves, acima exemplificados, ainda há um constatado déficit na produção, bem assim uma falta de consolidação acadêmica da mesma. (VERONESE, 2011).

Essa insuficiência causa, segundo lição de Veronese, dois problemas fundamentais ao direito, quais sejam, uma dificuldade de reconhecimento acadêmico por outras áreas e a dificuldade de institucionalização de infraestrutura, resultando no seguinte ciclo vicioso:

Pouca verba é direcionada à área de direito porque ela é vista como "menos acadêmica"; (2) ela se torna "mais fraca" ("academicamente menos" reconhecida pelos outros pesquisadores) porque produz qualitativamente menos e também por ter menos recursos; e (3) por ser mais "fraca" e "menos acadêmica", ela recebe pouca verba.(VERONESE, 2011, p. 177).

É a partir deste panorama de insuficiência de pesquisas científicas empíricas em direito que se abordará a cultura excessivamente "manualesca" como uma das causas da problemática. 


\section{A CULTURA DE MANUAIS COMO POSSÍVEL CAUSA DA ESCASSEZ DE PESQUISA EMPÍRICA NO DIREITO NO BRASIL}

Inicialmente, é necessário estabelecer que a hipótese aqui apresentada como causa para a baixa produção de pesquisa de campo em direito não é a única, de modo que a eventual superação da mesma não representaria a solução da questão. Em verdade, o recorte epistemológico escolhido se presta a analisar mais uma das hipóteses para problemática tão complexa, que se coloca ao lado de várias outras, algumas que já estão a caminho de uma solução, e outras que ainda não foram superadas.

Dito isso, cabe esclarecer quais as origens da cultura manualesca e em que consiste tal cultura, cujo alcance ainda hoje repercute, não apenas no ensino de graduação, como se poderia pensar. É que, por via oblíqua - isto é, pela mentalidade dogmatizante que dela decorre - suas ressonâncias acabam alcançando até mesmo o âmbito da pesquisa jurídica stricto sensu. O manual, para o ensino do Direito na graduação, apresenta-se quase como uma instância definitiva do aprendizado, norteando dogmaticamente o que deve ser apreendido sobre determinado tema, de forma refratária à possibilidade dequestionamentos. Não é de admirar que os bacharéis, ao adentrarem no universo da pesquisa de stricto sensu, permaneçam compreendendo a pesquisa jurídica como aquela que "compila" o que estatuem os doutrinadores. Ou seja, ainda que se abandonem os manuais de graduação, a postura assujeitada dos pesquisadores permanece inalterada, limitando-se a compilar opiniões consagradas de teóricos renomados em nível de pós-graduação.

De fato, é cultura fartamente difundida no meio acadêmico das faculdades de direito esse estudo da dogmática através dos manuais, o que acaba por gerar um ciclo vicioso que, a cada volta, afasta a ciência do direito das pesquisas de campo. A professora Baptista bem explica esse fenômeno:

No Direito, a importância disso se multiplica, uma vez que a única forma oficialmente difundida de compreender o sistema é lendo livros e manuais de pessoas "autorizadas" a escrever sobre determinados assuntos, independentemente de a realidade das práticas judiciárias nos mostrar, todos os dias, que o que está nos manuais não existe nos Tribunais. (BAPTISTA, 2010, p. 131).

Esse ciclo vai seguindo seu caminho, meio que tangenciando a realidade, sem que a necessária interseção aconteça, aprofundando, dessa forma, a tradição de manual, aqui representada pela forma de "consagração" científica do direito: ao contrário das outras áreas do conhecimento, ${ }^{7}$ o estudioso do direito, o jurista, o doutrinador, se preocupa primordialmente em legitimar o seu pensamento teórico com base nele mesmo, desqualificando os críticos, e a seu status é medido pela contraposição às críticas, só que, de novo, com base em argumentos teóricos, internos. A professora mencionada acima expõe a preocupação predominante dos doutrinadores:

7 Nas outras áreas científicas, o mérito, a consagração do estudioso é fruto de uma produção científica que redunde descobertas valiosas no mundo real, que venham a facilitar e ajudar a humanidade, ou seja, pesquisas inovadoras que abracem perspectivas práticas. Tome-se como exemplo o prêmio Nobel: a imensa maioria dos juristas que alcançaram a láurea o fizeram não pela produção científica em direito, e sim por sua atuação em outras áreas, como a política. 
Transpondo isso ao Direito, verificamos que, de fato, a preocupação dos "doutrinadores" em legitimar o seu saber é maior do que o compromisso com o conteúdo daquilo que sustentam. Muitas vezes, a competição pela consagração se resume ao contraditório de teses por si só, em vez de representar um efetivo comprometimento com a produção intelectual. Os "juristas” disputam a produção do "saber jurídico" de forma tal que - a busca desse mencionado status de criador de um conhecimento exclusivo e único - leva à mútua desqualificação. Ou seja, ganhar a disputa interna do campo pela criação do "saber jurídico" supõe, necessariamente, desqualificar a tese oposta; e esse inesgotável duelo de opiniões resulta em contradições e anulações recíprocas. (BAPTISTA, 2010, p. 134).

Tal panorama de construção de conhecimento fechado que os manuais encerram acaba por engessar a ciência jurídica, objetando o tensionamento necessário à produção científica de ponta, incluindo-se aí a pesquisa empírica. A legitimação do cientista jurídico não vem, na maioria dos casos, na comprovação ou verificação de suas ideias na realidade prática, e tampouco as críticas se baseiam nesses elementos para, por exemplo, demonstrar a falibilidade empírica de uma tese.

Parece reduzir-se esse embatea um meroargumento deautoridade, que éestabelecido pelo manual e não é posto à prova, investigado empiricamente. Este argumento parece estar arraigado nos ambientes jurídicos, sendo emblemática, para ilustração, a seguinte frase de um Ministro do Superior Tribunal de Justiça: "Precisamos estabelecer nossa autonomia intelectual, para que este Tribunal seja respeitado." (BARROS, 2003)

Esse argumento de autoridade decorrente da cultura de manuais é claramente vinculado à uma tradição romano-germânica de excessivas codificações, tanto que tal realidade é sentida também em outros países de matriz jurídica similar:

La cultura de lós manuales impide justamente eso: que los problemas reales y prácticos se conviertan em problemas jurídicos. La forma tradicional de enseñar derecho es, de hecho, empobrecedora, pues los manuales difícilmente presentan las cuestiones jurídicas como problemas propiamente dichos. En general los manuales, y por imitación muchos trabajos jurídicos, comienzan con definiciones. (LOPES, 2006, p. 55). ${ }^{8}$

Ante tal realidade fechada, o terreno se mostra árido para cientistas que se dediquem à produção de uma PED, sendo esta certamente uma das razões para a constatada baixa produção empírica da área. De fato, a pesquisa empírica desafia o manual, o código, a "melhor doutrina”. Quem realiza pesquisa científica de campo pode se deparar com a desconstrução de verdades tidas como absolutas, desembocar num emaranhado de dados inusitados: pode até, imagine, contradizer o vade-mécum!... Há, parece, certo receio da realidade, embora, como demonstrado anteriormente, isso esteja lentamente se modificando.

Pois bem. Ocorre que, se não houver uma desconstrução do imaginário que permeia a pesquisa jurídica no Brasil, não se poderá aproximar a pesquisa jurídica de um paradigma de cientificidade em níveis mais satisfatórios. Com efeito, o conhecimento científico deve ter como ponto de partida a solução de um problema, uma pergunta a ser respondida, pois como ensina Karl Popper, "não existe conhecimento sem problemas e nem problemas sem conhecimento." (POPPER, 2004, p. 14).

8 Manuel Atienza, no prólogo desta publicação, faz constatação semelhante quanto à pesquisa em direito. 
Diz Popper com singular propriedade:

Se é possível dizer que a ciência, ou o conhecimento, "começa" por algo, poder-se-ia dizer o seguinte: o conhecimento não começa de percepções ou observações ou de coleção de fatos ou problemas. Poder-se-ia dizer: não há nenhum conhecimento sem problemas; mas, também, não há nenhum problema sem conhecimento. Mas isto significa que o conhecimento começa da tensão entre conhecimento e ignorância. Portanto, poderíamos dizer que, não há nenhum problema sem conhecimento; mas, também, não há nenhum problema sem ignorância. Pois cada problema surge da descoberta de que algo não está em ordem com nosso suposto conhecimento; ou, examinando logicamente, da descoberta de uma contradição interna entre nosso suposto conhecimento e os fatos; ou, declarado talvez $m$ ais corretamente, da descoberta de uma contradição aparente entre nosso suposto conhecimento e os supostos fatos (POPPER, 2004, p. 15).

Ocorre que a visão popperiana, na qual se enfeixa o atual paradigma de cientificidade encontra grande refração em um ambiente dominado pelo culto exacerbado ao argumento de autoridade. Seria necessário instaurar no ambiente da academia jurídica uma nova mentalidade de pesquisa, em que se naturalizassem o debate, a crítica, o teste e o falseamento de ideias, sem a preocupação atual de se ferir suscetibilidades. Neste sentido, a lúcida opinião de Roberto Kant Lima e Bárbara Gomes Lupetti Baptista:

Os discursos produzidos pela dogmática - baseados essencialmente em opiniões em vez de dados - ainda sustentam a produção "teórica" do Direito, embora não encontrem qualquer correspondência empírica. Isso tem como consequência o fato de que ler livros e manuais de Direito não é suficiente para construir uma percepção adequada do campo jurídico e tampouco permite entender a lógica do nosso sistema judiciário. [...] Ao contrário da construção dogmática do Direito, o estudo das práticas judiciárias, realizado a partir de pesquisas etnográficas de caráter antropológico, permite uma interlocução com o campo empírico que incorpora à produção do saber jurídico os significados que os operadores do campo atribuem à Lei e às normas, possibilitando uma percepção, não apenas mais completa, como também mais democrática, dos fenômenos e institutos jurídicos (LIMA; BAPTISTA, 2010, online).

Acrescente-se a esse ambiente de desconfiança e refração, as dificuldades oriundas da complexidade inerente à pesquisa de campo. Em outros termos, mesmo aqueles acadêmicos que se mostrem abertos às possibilidades enriquecedoras da pesquisa de campo, mesmo estes, precisarão se reinventar como pesquisadores, a partir de uma atitude de protagonismo e autonomia na busca de um savoir-faire que a maior parte da academia jurídica não domina com segurança. Neste contexto ressalta Paulo Eduardo Alves da Silva:

[...] realizar pesquisa empírica é uma tarefa muito mais complexa do que se imagina. A discussão, o planejamento, a elaboração de instrumentos, a realização de testes, os treinamentos, a coleta em si, a sistematização dos dados, a checagem, o retorno a campo, as multivariadas análises, as reanálises, a elaboração dos relatórios... Tudo isso toma meses, às vezes anos, de intenso trabalho e, principalmente, de trabalho em grupo, coletivo - o que, sabemos, é um considerável incremento de complexidade frente à tradicional pesquisa de gabinete. Pois bem, e quando vencida toda essa etapa da realização da pesquisa, há toda uma nova fase, um outro desafio, talvez até mais complexo: saber usar os seus resultados, o que implica uma questão de cultura, de formação jurídica; como usar os dados das pesquisas empíricas? (CUNHA; SILVA, 2013, p.18). 
Nesse mesmo quadrante, alerta Roberto Fragale Filho, apontando importantes fatores que dificultam a criação de uma cultura de pesquisa de campo no Brasil, destacando-se os seguintes aspectos:

A prevalência da dogmática e os manuais; a falta de controle sobre o trabalho de campo e os custos altos para a realização de um trabalho coletivo; instabilidade profissional; ausência de tempo e treinamento, e ainda citando Alexandre Varonese (FRAGALE FILHO; VARONESE, 2015, online), afirma que a pesquisa de campo requer prática constante e recursos altos para o custeio (FRAGALE FILHO; VARONESE, 2004).

Como se pode verificar, nos limites definidos para este estudo, não poderiam ser analisadas as possíveis soluções para um problema multifacetado, atravessado por diferentes fatores, que desafiam ulteriores aprofundamentos. Por agora, o presente estudo limita-se à apresentação de uma hipótese sobre a problemática da baixa incidência de pesquisa de campo no Brasil, a qual pode estar relacionada com a cultura excessivamente manualesca que impregna a pesquisa jurídica, podendo consistir em uma das causas para a escassez de PED no Brasil. Espera-se que estudos posteriores possam retomar e enfrentar tal hipótese, submetendo-a a testes, na expectativa de que o aprofundamento da presente discussão possa ensejar soluções engendradas por outros pesquisadores.

\section{CONCLUSÕES}

Ao analisar o histórico da pesquisa de campo em direito na realidade norteamericana, verifica-se uma consistente cultura de pesquisa empírica na área jurídica que data do início do século passado, com o movimento do realismo jurídico, e vários outros que se seguiram. Em uma tradição jurídica de matriz consuetudinária, como a anglosaxônica, a pesquisa da realidade parece ter ganho maior relevo, sobretudo pela constante necessidade de se recorrer ao histórico argumentativo anterior para a construção de novos conhecimentos jurídicos.

Essa realidade tomou direção oposta nas culturas jurídicas de matrizes romanogermânicas, excessivamente forjadas em codificações e dependente de manuais. No Brasil, salvo alguns casos isolados, somente nas duas últimas décadas, é que o meio acadêmico do direito começou a valorizar e incentivar a PED. Essa tendência, entretanto, ainda se mostra tímida e escassa, especialmente quando se compara o direito com outras áreas científicas de produção de conhecimento.

Historicamente, verificou-se um isolamento do direito em relação a outras ciências, o que prejudicou sobremaneira a sua produção acadêmica, que ainda é vista com desconfiança por cientistas de outras áreas, como a Sociologia e a Antropologia.

Uma das causas dessa escassez de pesquisa de campo no direito parece apontar para a excessiva cultura de manual presente no imaginário jurídico nacional. De fato, como se pôde constatar, o ensino do direito tem sua matriz forte nos manuais, de sorte que os argumentos de autoridade neles contidos geram verdadeiro engessamento na produção científica dessa área.

Muitos doutrinadores justificam suas teorias de modo autorreferente, apoiando suas ideias numa lógica de circularidade, que se retroalimenta a partir de si mesma, ou, 
quando muito, a partir de um solo teórico que se limita aos mesmos procedimentos. Dessa forma, a pesquisa jurídica mantém-se pouco permeável à realidade fática, focando suas energias em um jogo agônico, pelo qual se pretende sobrepujar argumentos opostos, em detrimento do compromisso científico de apoiar suas investigações em dados e evidências factuais.

Assim, a disseminação e a naturalização da mentalidade "manualesca" acaba por criar um ciclo vicioso, cujo resultado é um estado geral de indiferença face à pesquisa empírica, o que explicaria - ao menos em parte - a baixa incidência de estudos de campo e sua falta de rigor científico, justamente numa área cujos estudos têm o potencial de afetar a vida real de todos os cidadãos.

\section{REFERÊNCIAS}

BACON, Francis. Novum organum. [S.1.]: eBooksBrasil, 2002. E-Book. Disponível em: <http://www.ebooksbrasil.org/eLibris/norganum.html>. Acesso em: 26 jun. 2017.

BAPTISTA, Bárbara Gomes Lupetti. A pesquisa empírica no Direito: obstáculos e contribuições. In: LIMA, Roberto Kant de; EILBAUM, Lucia; PIRES, Lenin (Org.). Conflitos, direitos e moralidades em perspectiva comparada. Rio de Janeiro: Garamond Universitária, 2010. v. 2. p. 127-152.

BARROS, Humberto Gomes de. Julgamento proferido no Agravo Regimental em Recurso especial n. 279.889-AL. Disponível em: <https://ww2.stj.jus.br/websecstj $/ \mathrm{cgi} /$ revista $/$ REJ.cgi $/$ C seq $=525558 \&$ tipo $=69 \&$ nreg $=200101540593 \& S e q C g r m a S e s s a o=\&$ CodOrgaoJgdr $=\& d t=20030407 \&$ formato=PDF\&salvar=false $>$. Acesso em: 26 jun. 2017.

CUNHA, Alexandre dos Santos; SILVA, Paulo Eduardo Alves (Coord.). Pesquisa Empírica em Direito. Rio de Janeiro: Ipea, 2013.

FRAGALE FILHO, Roberto; VARONESE, Alexandre. Considerações sobre o problema da pesquisa empírica e sua baixa integração na área de direito: a tentativa de uma perspectiva brasileira apartir da avaliação dos cursos de pós-graduação do Rio de Janeiro. 2015. Disponível em: <http://www.pge.ms.gov.br/wp-content/uploads/ sites/48/2015/o3/Considera $\% \mathrm{C}_{3} \% \mathrm{~A}_{7} \% \mathrm{C}_{3} \% \mathrm{~B}_{5}$ es_sobre_o.pdf $>$. Acesso em: 14 jun. 2017 .

FRAGALE FILHO, Roberto; VARONESE, Alexandre. A Pesquisa em Direito: diagnósticos e perspectivas. Brasília: RPG, 2004.

GEORGE, Tracey E. An empirical study of empirical legal scholarship: the top law schools. Indiana Law Journal, v. 81, n. 1, p. 141- 161, 2005. Disponível em: <https://ssrn.com/abs tract $=775864>$. Acesso em: 22 jun. 2017.

HORTA, Ricardo de Lins e; ALMEIDA, Vera Ribeiro de; CHILVARQUER, Marcelo. Avaliando o desenvolvimento da pesquisa empírica em direito no brasil: o caso do projeto pensando o direito. Revista de Estudos Empíricos em Direito, São Paulo, v. 1, n. 2, p. 162-183, 2014.

JARDIM, Guilherme Duarte. Mapeamento da produção de pesquisa em direito no Brasil 
(1998-2012). In: ENCONTRO DE PESQUISA EMPÍRICA EM DIREITO, 4., 2014, Ribeirão Preto. Anais... Ribeirão Preto: REED, 2014. p. 173-192.

KELSEN, Hans. Teoria pura do direito. 8. ed. São Paulo: WMF Martins Fontes, 2009.

LEEUW, Frans L., Empirical legal research: the gap between facts and values and legal academic training. Utrecht Law Review, Netherlands, v. 11, n. 2, p. 19-33, 2015. Disponível em: <https://ssrn.com/abstract=2630043>. Acesso em: 23 jun. 2017.

LEITER, Brian. American legal realism. In: GOLDING, Matin P.; EDMUNDSON, William A. The blackwell guide to the philosophy of law and legal theory. Oxford: Blackwell, 2004. p. 50-66.

LIMA, Roberto Kant; BAPTISTA, Bárbara Gomes Lupetti. O desafio de realizar pesquisa empírica no direito: uma contribuição antropológica. 2010. Disponível em: <http://www.uff.br/ineac/sites/default/files/o_desafio_de_realizar_pesquisa_ empirica_no_direito.pdf $>$. Acesso em: 15 jun. 2016.

LOPES, José Reinaldo de Lima. Regla y compás, o metodología para un trabajo jurídico sensato. In: COURTIS, C. (Org.). Observar la ley: ensayos sobre metodología de la investigación jurídica. Madrid: Trotta, 2006. p. 41-67.

MILES, Thomas J.; SUSTEIN, Cass R. The new legal realism. University of Chicago Law Review, Chicago, v. 75, n. 2, p. 831-851, 2008. Disponível em: <https://ssrn.com/ abstract $=1070283>$. Acesso em: 22 jun. 2017.

NOBRE, M. Apontamentos sobre a pesquisa em direito no Brasil. São Paulo: Publicações EDESP/FGV, 2004.

POPPER, Karl. Lógica das ciências sociais. Tradução Estevão de Rezende Martins. 3. ed. Rio de Janeiro: Tempo Brasileiro, 2004.

ROSS, Alf. On law and justice. Berkeley: University of California Press, 1959.

SCHLEGEL, John Henry. American legal realism and empirical social sciences. Chapel Hill: University of North Carolina Press, 1995.

SILVA, Fábio de Sá e. Vetores, desafios e apostas possíveis na pesquisa empírica em direito no Brasil. Revista de Estudos Empíricos em Direito, São Paulo, v. 3, n. 1, p. 24-53, jan. 2016.

SUCHMAN, Mark C.; MERTZ, Elizabeth. Toward a new legal empiricism: empirical legal studies and new legal realism. Annual Review of Law and Social Science, v. 6, p. 555-579, 2010.

VERONESE, Alexandre. O papel da pesquisa empírica na formação do profissional do direito. Revista OABRJ, Rio de Janeiro, v. 27, p. 171-218, jan./jun. 2011. 